\title{
PROPRIEDADE DA TERRA E PODER NO BRASIL NA OBRA DE JOSÉ DE SOUZA MARTINS
}

\section{LAND OWNERSHIP AND POWER IN BRAZIL IN THE WORK OF JOSÉ DE SOUZA MARTINS}

\author{
Janaína Tude Sevá* \\ João Vitor Martins Lemes ${ }^{* *}$
}

\begin{abstract}
Resumo: O presente artigo pretende fazer uma síntese sobre o tema da propriedade da terra na obra e pensamento de José de Souza Martins e, a partir daí, refletir sobre como terra e poder perpassam, entrelaçados, a sociedade brasileira. Evidente que sua bibliografia, por demais extensa, abarca outras questões atreladas ao tema escolhido e que permearão este texto no seu desenrolar, sobretudo no que diz respeito à constituição dos sujeitos históricos por um lado, e às noções distintas de direitos com as quais operam, por outro. A estrutura do presente trabalho percorrerá alguns dos títulos e artigos do autor, tais como "A Imigração e a crise no Brasil Agrário" (1973), "Capitalismo e Tradicionalismo" (1975), "O Cativeiro da Terra" (1979), "Expropriação e Violência" (1980), "A Militarização da Questão agrária" (1984), "O Poder do Atraso" (1994), "Fronteiras. A degradação do Outro nos confins do Humano" (1997), "Reforma Agrária: o impossível diálogo" (2000). Numa perspectiva diacrônica que se propõe seguir nesta exposição sobre a bibliografia do autor, percebe-se movimentos de incorporação e de abandono de algumas ideias e ou terminologias, assim como posicionamentos políticos e pessoais (estes últimos não serão objeto desta reflexão). Já por meio de uma análise sincronizada de processos, relações e instituições sociais, podese apreender os marcos teóricos e metodológicos do autor. Ao tratar da propriedade da terra enquanto processos, relações e instituições sociais estaremos identificando as singularidades históricas do caso brasileiro de desenvolvimento capitalista e da formação de uma classe dominante no campo
\end{abstract}

Palavras-chaves: Propriedade da terra, Poder, Direitos, José de Souza Martins.

\begin{abstract}
The present article intends to make a synthesis on the subject of land ownership in the work and thought of José de Souza Martins and, from there, reflect on how land and power permeate, intertwined, Brazilian society. It is evident that his bibliography, which is too extensive, covers other issues related to the theme chosen and will permeate this text in its development, especially with regard to the constitution of historical subjects on the one hand, and the different notions of rights with which they operate, for another. The structure of this paper will cover some of the author's

\footnotetext{
* Doutora e Mestre em Ciências Sociais em Desenvolvimento, Agricultura e Sociedade (CPDA/UFRRJ), Graduada em Ciências Sociais (UFF). Professora Adjunta da UFG/Regional Goiás. Contato: janainatudeseva@gmail.com

** Doutorando em Antropologia Social (PPGAS/UFG), Mestre em Direito Agrário (PPGDA/UFG), Graduado em Direito (UFG). Professor Assistente da UFT/Campus Arraias. Contatp: martins.joaovitor@yahoo.com.br.
} 
titles and articles, such as "Immigration and the Crisis in Brazil Agrarian" (1973), "Capitalism and Traditionalism" (1975), "The Captivity of the Earth" Expropriation and Violence "(1980)," The Militarization of the Agrarian Question "(1984)," The Power of Delay "(1994)," Frontiers. The degradation of the Other in the confines of the Human "(1997)," Agrarian Reform: the impossible dialogue "(2000). In a diachronic perspective that is proposed to follow in this exposition about the author's bibliography, one notices movements of incorporation and abandonment of some ideas and / or terminologies, as well as political and personal positions (the latter will not be object of this reflection). Already through a synchronized analysis of processes, relations and social institutions, one can apprehend the theoretical and methodological frameworks of the author. In dealing with land ownership as processes, relations and social institutions we will be identifying the historical singularities of the Brazilian case of capitalist development and the formation of a dominant class in the field.

Key-words: Land Property, Power, Rights, José de Souza Martins.

\section{INTRODUÇÃO}

“A História não é apenas um conflituoso processo de rupturas. É também, um processo de contínuas recriações e reiterações"

(MARTINS, 2000)

O presente artigo pretende fazer uma síntese sobre o tema da propriedade da terra na obra e pensamento de José de Souza Martins e, a partir daí, refletir sobre como terra e poder perpassam, entrelaçados, a sociedade brasileira. Evidente que sua bibliografia, por demais extensa, abarca outras questões atreladas ao tema escolhido e que permearão este texto no seu desenrolar, sobretudo no que diz respeito à constituição dos sujeitos históricos por um lado, e às noções distintas de direitos com as quais operam, por outro. A estrutura do presente trabalho percorrerá alguns dos títulos e artigos do autor, tais como "A Imigração e a crise no Brasil Agrário" (1973), “Capitalismo e Tradicionalismo" (1975), "O Cativeiro da Terra" (1979), "Expropriação e Violência" (1980), “A Militarização da Questão agrária" (1984), "O Poder do Atraso" (1994), "Fronteiras. A degradação do Outro nos confins do Humano" (1997), "Reforma Agrária: o impossível diálogo" (2000).

Numa perspectiva diacrônica que se propõe seguir nesta exposição sobre a bibliografia do autor, percebe-se movimentos de incorporação e de abandono de algumas ideias e ou terminologias, assim como posicionamentos políticos e pessoais 
(estes últimos não serão objeto desta reflexão). Já por meio de uma análise sincronizada de processos, relações e instituições sociais, pode-se apreender os marcos teóricos e metodológicos do autor. Ao tratar da propriedade da terra enquanto processos, relações e instituições sociais estaremos identificando as singularidades históricas do caso brasileiro de desenvolvimento capitalista e da formação de uma classe dominante no campo $^{1}$.

Isto porque no nosso desenvolvimento nacional, na esfera dos direitos, o poder político oligárquico, de fazendeiros e do empresariado rural (e por vezes de elites urbanas) se deu pela manutenção do monopólio da propriedade privada da terra. Dentro de um sistema de governo democrático, o poder político ainda se encontra ligado à formas capitalistas de propriedade da terra, e as relações de poder e dominação social e econômica estão historicamente fundamentadas no seu monopólio.

\section{TERRA COMO PROCESSO SOCIAL: EXPROPRIAÇÃO, LUTA POR TERRA, RECONHECIMENTO JURÍDICO E EXCLUSÃO DE DIREITOS}

"Num regime de terras livres, o trabalho tinha que ser cativo;
num regime de trabalho livre, a terra tinha que ser cativa"

(MARTINS, 1979)

Desde os escritos inicias de Martins, quando aborda a história da formação da sociedade brasileira sob os moldes de um projeto de Nação e quando remonta à Lei de Terras de 1850 e à Abolição da Escravidão em 1888, nota-se uma preocupação central na compreensão das peculiaridades e contradições do processo de desenvolvimento desigual da sociedade brasileira, uma sociedade eminentemente agrária e em vias de urbanização. Ao estudar a implementação deste projeto nacional elaborado com base num modelo modernizador das relações de trabalho, através de um plano de imigração e da criação de núcleos coloniais, o autor enfatiza a importância de se estudar a sociedade a partir de seus processos periféricos e não centrais.

Compreender o capitalismo no Brasil a partir de suas peculiaridades históricas e culturais que evidenciou, segundo o autor, a necessidade teóricometodológica "[...] de reconhecer no atrasado, no anômalo, no marginal a mediação que oferece a compreensão mais rica do processo histórico e também indica o lugar 
Propriedade da terra e poder no Brasil na obra de José de Souza Martins

histórico de bloqueios e resistências ao desenvolvimento social" (MARTINS, 1997, p. $145)$.

Um dos saltos intelectuais da carreira do autor foi a crítica à visão dualista de desenvolvimento ${ }^{2}$, elaborada na Escola de Sociologia da USP, retomando a noção de desenvolvimento desigual para entender as contradições básicas do nosso processo histórico. Em "A Imigração e a Crise no Brasil Agrário" Martins identifica o Brasil como uma sociedade diversificada socialmente em que "[...] mesmo as sobrevivências, como as dos antigos sitiantes e posseiros caipira, são reequacionadas historicamente, determinando-se através de uma nova mediação: a da propriedade capitalista da terra" (MARTINS, 1973, p. 16).

A ideia de desenvolvimento desigual, vinculada a de capitalismo periférico e pautada nas noções de expropriação do excedente, economia do excedente, exclusão integrativa e tradicionalização, foi desenvolvida no conjunto de artigos publicados em 1975, sob o título de "Capitalismo e Tradicionalismo. Estudos sobre as contradições da sociedade agrária no Brasil". Isso para explicar como a modernização da agricultura, um dos primeiros passos ao desenvolvimento nacional e à própria industrialização, teve como alicerce, dentre outros, um "agrarismo rústico e o caipira". "É, pois, o estabelecimento tradicional que se constitui num dos pontos de apoio da efetivação do mundo capitalista e urbano no país" (MARTINS, 1975, p. 13).

Ao focar suas pesquisas sobre o rural, acaba apresentando seus princípios teórico-metodológicos, como a ideia de configuração histórica que utiliza ao definir o problema agrário como uma preocupação do mundo urbano na medida em que este depende daquele ${ }^{3}$. É a partir dos processos de instituição da propriedade privada e das relações capitalistas de produção na sua feição brasileira que Martins analisa o movimento pendular de transferência de recursos e poder entre os setores agrícola e industrial, ação através da qual o Estado garantia um equilíbrio das forças políticas em disputa, mais especificamente das elites agrária e urbana. É fundamentalmente na institucionalização da propriedade privada da terra que o autor enxerga a chave para entender do desenvolvimento desigual do capitalismo no Brasil, a partir de seus referenciais teóricos como Trotski, Marx e, principalmente, Henri Lefebvre (MARTINS, 1980, p. 12). Neste sentido, analisa o autor, o desenvolvimento do 
capitalismo no campo veio onerar e subordinar o trabalhador rural e o migrante ao capital, seja na forma do assalariamento, seja na forma do arrendamento.

Assim, mesmo diante das ações do Estado de ampliação dos direitos trabalhistas e regulamentação sobre o direito de propriedade (que fariam parte do arsenal jurídico e administrativo de qualquer Estado Moderno), a consolidação desse mercado acelerou o processo de empobrecimento de posseiros, colonos e demais categorias de trabalhadores do campo, sobretudo pela institucionalização da propriedade privada da terra como mediadora das relações de trabalho. Terra para negócio e não para trabalho, diria José de Souza Martins, "fonte de pobreza e não de riqueza" (MARTINS, 1973).

Instalava-se a partir de então o conflito entre as distintas noções e práticas de direito à terra, já que a nova lei trazia consigo fortes restrições às formas existentes (posses, terras comuns, territórios indígenas, morgadio, etc.) e submetia o acesso à terra ao pagamento seja da própria terra seja do seu uso, caracterizando-a enquanto uma mercadoria:

\footnotetext{
Na verdade, o que caracteriza a penetração do capitalismo no campo não é a instauração de relações sociais de produção típicas formuladas em termos de compra e venda de força de trabalho por dinheiro. O que a caracteriza é a instauração da propriedade privada da terra, isto é, a mediação da renda capitalizada entre o produtor e a sociedade (MARTINS, 1975 p.49-50).
}

A luta entre essas distintas formas de apropriação da terra trouxeram à tona as diferentes racionalidades, culturas e, consequentemente, noções de propriedade que mais cedo ou mais tarde se deparariam com uma sistemática própria ao capitalismo: normatização e burocratização das relações sociais, deveres e direitos do proprietário e do não proprietário, mediadores políticos, dentre outros. A expansão das formas capitalistas, no entanto, como ressaltou ao longo de quase toda sua obra, foi (e ainda é) extremamente capaz de adequar e reapropriar formas não capitalistas de produção ${ }^{4}$, assim como a propriedade privada teve um valor conceitual de trazer a noção de um processo social (o desenvolvimento capitalista) cujo resultado mais evidente é a expropriação de pessoas de suas terras, mediante outro processo que, dialeticamente, legitima a forma capitalista de apropriação da terra e do trabalho (MARTINS, 1975; $1979 ; 1980)$.

A pequena propriedade aparece como expressão do desenvolvimento do capitalismo no campo em termos de subordinação, expropriação e exploração do 
Propriedade da terra e poder no Brasil na obra de José de Souza Martins

trabalho pelo capital, tendo como mediador a renda capitalizada da terra. A forma jurídica da propriedade privada é a expropriação e tem a luta pela terra como os processos de diferenciação social entre posseiros e proprietários. E a duplicidade de ações sociais evidencia-se nos diferentes fins que cada empreendimento agrário imprime, seja pessoal, seja capital, “[...] isto é, prevalecem tanto ações em que os fins pessoais coincidem com os fins do capital, como ações em que os fins fundamentais são os pessoais (valores, emoções, rotina)" (MARTINS, 1975, p. 19).

A ideia de fronteira, que dá nome a um de seus livros, também nos reporta a sua reflexão sobre a propriedade privada enquanto processo social, “[...] como momento de uma totalidade dialética e, portanto, momento de contradição e lugar de conflito" (MARTINS, 1997, p. 155). Num tom mais ácido, “A história recente da fronteira é uma história de destruição. Mas é também uma história de resistência, de revolta, de protesto, de sonho e de esperança” (MARTINS, 1997, p. 147). Ao considerar o processo de expansão tanto de frentes populacionais como do capitalismo no campo, mais especificamente na Amazônia brasileira, Martins apropria-se da noção de desencontro entre tempos históricos distintos, que herdou de Henri Lefebvre e Florestan Fernandes, para explicar dialeticamente o avanço das formas capitalistas de ocupação do solo sobre as demais existentes, sejam elas indígenas ou tradicionais (MARTINS, 1996).

O que escapa aos modelos explicativos europeus sobre a universalização do capital é abordado pelo autor como fazendo parte deste processo de universalização, porém de forma marginal, desigual e definitivamente conflituosa. $\mathrm{O}$ autor nega fórmulas básicas de tendências históricas, mas aponta as peculiaridades do processo de desenvolvimento do capitalismo no campo no Brasil, caracterizado dentre outros pela noção de desenvolvimento desigual e de reprodução capitalista de relações não capitalistas de produção. Mantêm-se a percepção de que há uma integração na relação entre diferentes, social e etnicamente falando, fortemente marcada por uma posição de marginalidade da sociedade ou grupo social "atrasados, milenaristas ou arcaicos" em relação ao modelo "mais avançado", ao qual devem se integrar. A integração é marginal por que é feita pelos "modernos ou atuais", é deles a mediação e dos outros a subordinação. Subordinação que não quer dizer necessariamente assalariamento ou proletarização de camponeses, índios ou posseiros (MARTINS, 1997), e sim de submissão de uma racionalidade a outra, de um modo de vida a outro. 
De fato os horizontes e as possibilidades históricas que Martins aponta na situação de fronteira estão contornados pelas diferentes formas de dominação sob as quais as pessoas se encontram, já que há a predominância do paradigma marxista do materialismo e das sobredeterminações da estrutura em sua análise. Entretanto, a expansão territorial do capital que se dá a partir da legitimação da propriedade privada da terra em detrimentos de outras formas de apropriação da mesma (e os conflitos decorrentes), não se restringem às formas jurídica ou econômica da dominação. Pelo contrário o embate entre valores culturais e sociais (históricos) sobre posse ou domínio da terra, o trabalho, as relações de troca, etc., é um dos aspectos mais enfatizados pelo autor em vários se seus títulos. E apesar de enfatizar o cotidiano e as lutas do campesinato, dos indígenas e das populações pobres do campo, não deixa de apontar a pluralidade de "[...] personagens, atividades econômicas e relações sociais específicas" (MARTINS, 1997, p. 192). Extrapola a análise tradicional classista e tece, sem abandonar o materialismo histórico e dialético, uma sociologia brasileira sobre o Brasil.

Em "Expropriação e Violência" (1980) é reforçada a reinterpretação, a partir da realidade empírica nacional, do modelo diádico da contradição Capital X Trabalho para a relação triádica Capital X Trabalho X Renda da Terra; apontando para uma diferenciação interna às classes sociais trabalhadoras da cidade e do campo, tanto em termos de valorização de seu trabalho e de seu produto, respectivamente, quanto “[...] os fundamentos da conduta e da consciência de um e de outro" (MARTINS, 1980, p. 14). Assim demonstra que a outra face do desenvolvimento das contradições capitalistas no campo, ou seja, da institucionalização da propriedade privada, é justamente o fortalecimento da empresa rural e a manutenção de classes dominantes no campo.

Há entretanto, salienta Martins, reações e contestações da forma jurídica da propriedade que se dão no plano da representação política, construídas num processo de diferenciação social entre posseiros, imigrantes e grandes proprietários. Ao mesmo tempo em que a propriedade privada da terra cria seus expropriados ela dá as condições de contraposição ao seu modelo jurídico, identificada por Martins na força social do campesinato que vem com o seu "direito construído na prática":

\footnotetext{
A fronteira não se esgota pela diluição das terras em favor de grandes empresas e proprietários levada a efeito pelo Estado capitalista. É verdade que ergue barreiras judiciais ao avanço territorial dos lavradores sem-terra. Mas, os lavradores do campo têm sua própria concepção de direito de propriedade, que faz levantarem-se subversivamente contra o direito proclamado e garantido pelo Estado em favor das classes dominantes" (MARTINS, 1980, p. 17-8).
} 
Propriedade da terra e poder no Brasil na obra de José de Souza Martins

Neste sentido, o Estado tem um papel fundamental na compreensão das transformações sociais decorrentes do processo de consolidação da propriedade privada da terra e da subsequente expropriação camponesa. A partir da análise desenvolvida no clássico "O Cativeiro da Terra", Martins define como contradição fundamental do desenvolvimento capitalista no Brasil a associação do capital à renda da terra, mediado pela ação do Estado. Um arcabouço legal foi instituído no sentido de tornar a propriedade privada da terra, para além de um ativo financeiro, um instrumento para garantia e acesso a inúmeros privilégios políticos e subvenções econômicas. Considerada em perspectiva histórica de longo prazo, a constituição da sociedade e do Estado no Brasil estão imbricadas ao domínio da terra, e o processo chamado de modernização das relações sociais (fim da escravidão, mercado livre, direitos individuais, estado laico) passa por várias configurações que atualizam um dinâmico ciclo de transformação da terra em renda territorial capitalizada (MARTINS, 1979).

A partir do momento em que, com a Lei de Terras de 1850, restringe o acesso à terra mediante pagamento em capital, o Estado assume para si uma noção liberal de direito de propriedade que é próprio à burguesia e ao modelo capitalista. Em decorrência desta adoção legal, inúmeros conflitos deflagram-se impondo ao próprio Estado medidas de incorporação da população rural em outros conjuntos de direitos, como forma de conter convulsões sociais. Dentre eles, e o mais importante, a própria ideia de liberdade e igualdade que como aparato legal, tornou livre o trabalhador e vinculou a exploração da mão de obra a um suposto novo mercado de trabalho separado e desvinculado das "antigas" relações tradicionais de moradia, morgadio e trabalho. Do ponto de vista da relação com os fazendeiros, consolida-se o monopólio privado da terra nas mãos de poucos capitalistas e rentistas, bem como a ideologia do trabalho que ao cabo levará o trabalhador a adquirir sua própria terra. Entretanto, é por esse mesmo mecanismo que o trabalhador que adquiri ou que ainda não foi expropriado de sua terra se submete à auto exploração para poder extrair lucro (no caso excedente comercializável) de seu trabalho. Nesse sentido:

As novas relações de produção, baseadas no trabalho livre, dependiam de novos mecanismos de coerção, de modo que a exploração da força de trabalho fosse considerada legítima, não mais apenas pelo fazendeiro, mas também pelo trabalhador que a ela se submetia. Nessas relações não havia lugar para o trabalhador que considerasse a liberdade como negação do 
trabalho; mas apenas para o trabalhador que considerasse o trabalho como uma virtude da liberdade (MARTINS, 1979, p. 18).

Ao garantir o monopólio da propriedade privada o Estado assegurou o controle social, político, ideológico e econômico da mão de obra bem como sua exploração permanente. Caracterizando-se como um Estado capitalista, trouxe para seu interior a gestão do conflito, assimilou espaços existentes e criou novos espaços de luta e representação dos sujeitos políticos. E, numa dimensão histórica, mesmo reestruturando o modelo democrático após vários períodos ditatoriais, continuou assumindo a tarefa de gerenciar a renda da terra.

Devo esclarecer que não se trata de uma definição neutra ou imparcial de Estado, tal como um aparelho vazio a ser preenchido; entretanto apesar da perspectiva marxista do autor ao considerar o estado como parte no conflito, não fica claro em sua obra uma concepção clara ou definitiva de Estado. Percebe-se, ao contrário, uma mudança de perspectiva, subentendendo-se que no século XIX o Estado assume uma posição que é própria das elites econômicas e políticas, ao passo que a partir do ano 2000 ele emerge como apenas um mediador, um Estado mínimo que pouco atua politicamente.

Em "Reforma agrária, o impossível diálogo", é perceptível que, ao implementar um ou vários projetos de modernização, o Estado no sentido político (democrático) e também no econômico (liberal), incorpora demandas populares (por exemplo a reforma agrária) "[...] como recurso institucional para atenuar os efeitos politicamente conservadores da propriedade da terra, que se manifesta nos problemas sociais, e para acelerar a modernização da elite fundiária e das oligarquias" (MARTINS, 2000, p. 120). Seguindo este raciocínio o Estado impõe restrições redutivas a posse privada (regulando formas de exploração do solo, dos recursos naturais e das relações de trabalho) no sentido de valorizar uma noção de função social da propriedade e de retomar para si o domínio do território nacional. Segundo o autor, mesmo as políticas de reforma agrária têm servido a este objetivo maior do Estado de controle territorial e não aos objetivos específicos das camadas populares e ou progressistas da sociedade. 
Propriedade da terra e poder no Brasil na obra de José de Souza Martins

\section{PROPRIEDADE DA TERRA COMO RELAÇÃO SOCIAL: TRABALHO OU NEGÓCIO? CONSERVAR OU MODERNIZAR?}

A partir das leituras teóricas de Henri Lefebvre, Martins recupera a dimensão histórica e relacional dos processos sobre os quais se debruça na Amazônia brasileira, e identifica a coexistência de mentalidades e modos de vida distintos. A isto denomina contemporaneidade da diversidade, preocupando-se com as "[...] diferenças que definem seja a individualidade das pessoas, seja a identidade dos grupos" (MARTINS, 1997, p. 159).

Entretanto é mais pela via weberiana, do que propriamente estruturalmarxista (ou althusseriana, bastante criticada pelo autor) que Martins tenta identificar os tipos sociais que são fruto deste desenvolvimento desigual, tanto quanto suas visões de mundo e o sentido de suas ações sociais no contexto de consolidação de um mercado de terras e de um mercado de trabalho. "Em parte o dilema é produzido pela conjugação de duas orientações teóricas que se contrapõem: a de Marx e a de Weber. O primeiro estava preocupado com o capitalismo enquanto modo de produção; o segundo enquanto tipo de ação" (MARTINS, 1975, p. 33).

É permanente a preocupação de Martins com os significados, valores e percepções que engendram e realimentam a vida dos trabalhadores, bem como a centralidade desses elementos para se entender os encontros e desencontros históricos de trabalhadores entre si, ou com os demais grupos sociais, por exemplo através da noção de comunidade. O conflito demarca posições (processo objetivo), mas são as interpretações (consciência) deste conflito pelos sujeitos que definem identidades ou os vínculos de marginalização (MARTINS, 1973). Aliás, as identidades, na maioria das vezes e segundo Martins, se definem justamente pelos vínculos de marginalização e não por reconhecimento mútuo ${ }^{5}$. Ao mesmo tempo que a definição do "nós" e "eles" está envolta por uma noção dualista já que passa pelo reconhecimento mútuo e pela resignificação de si em relação ao outro. É um eterno fazer-se e refazer-se grupo, comunidade, na busca pela terra:

\footnotetext{
Ela tende a se definir no ambiente do ajustamento precário a uma nova situação decorrente da expulsão, a um novo relacionamento do homem com a natureza, frequentemente envolvendo perda cultural, realidades novas que impõem redefinição de costumes e tradições. (...) A busca tem um forte caráter comunitário (MARTINS, 1997, p. 194).
} 
Outro elemento que caracteriza as relações sociais e a formação identitária dos grupos e indivíduos é a situação de conflito na perspectiva das alteridades decorrentes desse "lugar de descoberta do outro e de desencontro" que é a fronteira para Martins (1997). Este desencontro, que de acordo com Martins se dá entre tempos históricos distintos, tem como resultado principal a legitimação da forma privada de apropriação da terra em detrimento das demais formas não capitalistas. É nesta situação de fronteira que as noções de direito sobre a terra entram em embate direto e as posições sociais desiguais se pronunciam os sujeitos históricos. Outro elemento constituinte desses sujeitos, protagonistas da situação de fronteira, para além das noções de direito ligado a terra, é a dimensão de conflitos por distintas concepções de destino, de projetos históricos ou ainda por versões ou possibilidades de ambos. As possibilidades se abrem exatamente na conflitividade, apesar de estarem tencionadas pela relação atrasado X moderno em que o moderno superaria o atrasado em termos de projeto e valores. Mesmo reconhecendo que há um projeto dominante e hierárquico, em sua análise o autor ressalta a capacidade criativa e a singularidade de cada conjunto de relações sociais.

No âmbito das relações sociais estabelecidas a partir das várias formas de posse e disputas pela terra, é relevante pensar o Estado ora como mediador de conflitos, ora como parte dos conflitos. Em períodos de governos autoritários o Estado assume de fato seu caráter autoritário e centralizador, além de mediador da aliança entre velhas oligarquias, Igreja e capital internacional. Já em momentos de governos democráticos o Estado como espaço legítimo de participação social e representação política aparece como eixo dos conflitos. Então, mesmo diante de atribuições democráticas do Estado e da forte presença de organizações da sociedade civil, onde supostamente há uma reformulação no modelo de ação estatal (ele fica mais liberal e menos centralizador) permanece a questão política e histórica da concentração fundiária como fonte de riqueza e poder no Brasil. (MARTINS, 2000, p. 87-131).

Mais uma vez Martins sugere como referencial teórico para analisar estas contradições entre estrutura e ação social a perspectiva weberiana da dominação legítima. Justificando, os possíveis desencontros entre a vontade individual e as vontades políticas dos grupos (instrumentos da representação legítima), a partir não apenas da incapacidade de Estado e mediadores em identificar e reconhecer projetos de vida e concepções de destino do trabalhadores rurais, camponeses e indígenas, mas 
Propriedade da terra e poder no Brasil na obra de José de Souza Martins

adesão a relações de exploração mesmo por necessidade de sobrevivência (MARTINS, 2000).

Tratemos agora, não mais da alteridade e dos desencontros históricos entre sujeitos políticos e suas distintas temporalidades, e sim das alianças políticas possíveis e pactos sociais estabelecidos em torno do projeto que previu a articulação entre propriedade privada da terra e o grande capital moderno. Nos termos de Martins, no Brasil o fazer história agrega duas dimensões importantes da questão fundiária: a dimensão política da propriedade da terra e a dimensão política da atuação dos que se envolvem na luta pela terra. A propriedade da terra aparece como centro histórico de um sistema político persistente, marcado pelo clientelismo, por formas de dominação tradicional de base patrimonial e que tem no conservador um instrumento de perpetuação do poder.

A partir do que o autor chama de Sociologia da História Lenta, que “[...] permite fazer uma leitura dos fatos e acontecimentos orientada pela necessidade de distinguir no contemporâneo a presença viva e ativa de estruturas fundamentais do passado" (MARTINS, 1994, p. 14), é possível apreender a relação entre transformação social e pensamento conservador. Este último não é imobilista, tornou-se "[...] ativo e transformador quando a sociedade tradicional foi posta em confronto com os efeitos socialmente desagregadores do progresso e da modernização” (MARTINS, 1994, p. $15)$.

Tendo como pressuposto a reprodução capitalista de formas não capitalistas de produção (ou ainda a superposição de racionalidades e tempos históricos distintos, denominado de diversidade da contemporaneidade), o autor apreende a aliança entre o capital moderno e a propriedade da terra no Brasil como uma aliança do atraso. A ideia de pacto social entre Estado e Oligarquias rurais, por exemplo, que perdurou desde os primórdios da república até a ditadura militar, nos anos 1960 e 70, prolongando-se nos anos seguintes da Nova República, reporta-se às relações políticas e de trabalho vigentes sob o controle desta oligarquia, baseadas no paternalismo, numa indistinção ente público e privado, na cultura do favor e da dívida política, e em práticas de corrupção e violência como mediadores do poder.

A terra enquanto relação social exprime as identidades e os antagonismos possíveis entre grupos e foi determinante em períodos históricos marcantes na sociedade 
brasileira. $\mathrm{O}$ fato das relações sociais se estabelecerem em função de um projeto de vida ou concepção de destino cujo objetivo seria a manutenção da posse da terra, nos termos do direito dominial (colonial), faz com que sujeitos históricos distintos, como posseiros e índios, possam compartilhar de uma mesma identidade política. Assim a resistência destes contra o avanço da propriedade privada da terra representa para Martins uma luta anticapitalista. Ao passo que aqueles que lutam pela inclusão na agenda democrática, por leis trabalhistas ou por melhoria das condições de vida e trabalho dentro do quadro legal vigente, como é o caso de partidos e sindicatos, estariam apenas reivindicando participar de forma bem posicionada no próprio capitalismo.

Há, entretanto, um dilema maior que ronda o pensamento do autor, no que diz respeito a ambiguidade vivenciada pelo pequeno produtor ou pelo agricultor familiar, já que se insere como trabalhador e como proprietário de terra e vive entre o subsistir e o produzir para o mercado. Em termos de consciência, como se comportaria este sujeito, se pensado a parti de sua posição econômico-social? Para Martins, trata-se de referenciais de classe social contrapostos (MARTINS, 2003, p. 12). Esta charada que o acompanha desde seus escritos iniciais sobre as formas políticas da luta e os projetos partidários e sindicais de transformação social, aparece de maneira mais refinada ao questionar quem são os "sujeitos ocultos" da reforma agrária e representam um impasse já que demonstra que a propriedade privada da terra antagoniza mesmo supostos companheiros de classe. Aqui no Brasil, nunca se superou a irracionalidade que a renda da terra representa na reprodução ampliada do capital, nem do ponto de vista do grande capital nem do ponto da luta dos trabalhadores do campo.

Ao chamar atenção para o "poder do atraso" (MARTINS, 1994) o autor lembra que quem teve a capacidade de transformar-se em força social por meio de um processo de modernização, ou renovação de suas armas políticas e ideológicas, para além da questão econômica, foi o fazendeiro. E o Estado aparece mais uma vez como intermediador desta renovação, já que sempre recorreu ao particular para fazer seus investimentos e prestar serviços, sempre acessou o patrimônio privado como garantia para investimentos de infraestrutura e, por meio de favores, regalias e práticas corruptas, trocava apoio político por incentivos econômicos:

Os políticos tradicionais e oligárquicos fazem política e se revigoram politicamente tornando-se indispensáveis através de instituições modernas. É impossível implementar qualquer programa de modernização do País sem pagar-lhes tributos políticos e econômicos (...). Os políticos modernos e modernizadores, que melhor expressam a mentalidade urbana e a idéia de 
Propriedade da terra e poder no Brasil na obra de José de Souza Martins

vínculo político racional entre o governo e os governados, não têm acesso ao poder se não fazem amplas concessões à mentalidade clientelista do eleitorado, e ao controle que têm dos votos os que tratam o eleitorado como se fosse rebanho político (MARTINS, 1994, p. 49).

\section{TERRA COMO INSTITUIÇÃO SOCIAL: ESTADO, PODER E REPRESENTAÇÃO POLÍTICA}

"É por meio dessa instituição que a economia colonial cria e redefine diversas categorias sociais, fazendo com que se revistam de formas e conteúdos congruentes com as necessidades de reprodução do capitalismo periférico"

(MARTINS, 1973)

Temos como instituições sociais aquele conjunto de elementos, materiais ou imateriais, que regulam das mais variadas formas a ação humana e as relações sociais. Neste sentido temos a propriedade da terra como instituição social que aglutina e orienta uma série de valores e condutas. Tratemos aqui, por títulos, alguns elementos delineadores da sociedade brasileira e que se tornaram verdadeiros mediadores políticos entre Estado e sociedade civil: o controle social institucionalizado, a representação política (partidária e sindical) e o autoritarismo político.

Em “Capitalismo e Tradicionalismo" Martins aborda o desenvolvimento das formas associativas e institucionais do capital no campo, que evidenciam a relação entre economia e política sobre tudo na formação dos grupos de interesse e suas interfaces com a propriedade privada. Em contraposição a empreendimentos agrícolas pouco ou nada geridos pela ação racional com relação a fins e supostamente distantes de uma noção empresarial de produção capitalista, uma considerável parte de fazendeiros e sitiantes reuniu-se em cooperativas e associações de produtores com intuito de controlar ou ao menos intervir política e legitimamente na esfera da comercialização dos produtos. Ampliava-se então o controle sobre as negociações, expandindo e diversificando os espaços de intervenção política e institucional, da produção para a comercialização e também atuando nas políticas de preço, que se fazia tanto criando espaços reconhecidos em institutos já existentes e fortemente vinculados ou regulados pelo Estado, como o Instituto Brasileiro do Café ou associações de classe; como “[...] indireta e não oficialmente [por] ter elementos seus em postos políticos locais (prefeitos 
e vereadores), relacionados com a concretização de uma infraestrutura econômica" (MARTINS, 1975, p. 18).

Temos aí, tanto no associativismo civil como no coorporativo, formas de controle social que nascem nos grupos e classes sociais dominantes com vistas a intervir nas esferas da produção e circulação de produtos, incluindo-se a própria força-detrabalho e o mercado de terras. Na visão do autor, o Estatuto da Terra de 1964 institucionalizou não apenas a propriedade privada da terra, mas sobretudo a empresa rural e a racionalidade capitalista; abrindo margem para o fortalecimento do associativismo empresarial que nos anos 1950, 60 e 70 atuaram intensivamente no sentido de garantir a modernização da agricultura mesmo que subordinada a lógica da industrialização e urbanização em escala nacional.

Já em “Os camponeses e a Política no Brasil” (1981), Martins discute questões relativas a representação política. Mais preocupado com os impasses destas formas de representação do ponto de vista dos subalternos, sua busca é para entender em que medida os trabalhadores, camponeses, posseiros, indígenas, dentre outros, precisariam desta mediação política; e em que medida os mediadores políticos, partido, sindicato e igreja, estariam traduzindo erroneamente as demandas desses a quem supostamente estavam defendendo. Assim, enquanto uns falavam de luta por direitos imemoriais, outros falavam de acesso a direitos trabalhistas ou a previdência rural. Dava-se o desencontro mais caro a Martins no plano da ação política coletiva e organizada, já que esta imprimia uma linguagem própria as lutas partidárias e sindicais, oriundas sobre tudo da ideologia e utopias comunistas, quase diametralmente opostas no entendimento do autor - da resistência cotidiana daqueles que estavam na terra propriamente. Pois a luta para os que já estavam na terra era, na leitura de Martins, uma luta anticapitalista, contra o direito de propriedade, uma luta por reconhecimento político; enquanto as formas dadas pelo partido, pelo sindicato e pela igreja apresentavam alternativas de sobrevivência por meio da inclusão neste modelo capitalista de direitos sociais e cidadania (MARTINS, 1981).

Por outro lado faltou a estes mediadores uma análise mais profunda das realidades vividas por cada um dos grupos que arvoravam representar, já que não se conseguiu apreender seus verdadeiros anseios, ou concepções de destino. A partir de uma transposição mecânica da teoria marxista sobre o desenvolvimento das forças produtivas do capitalismo para a realidade brasileira, focaram as contradições no campo 
Propriedade da terra e poder no Brasil na obra de José de Souza Martins

na relação capital $\mathrm{X}$ trabalho, enquanto o modelo de análise mais apropriado para $\mathrm{o}$ nosso caso seria triádico, ou seja, esta contradição básica está mediada pela renda da terra. Não teria sido o capital em si a criar uma classe de trabalhadores no campo, mas a implementação da propriedade privada da terra e sua imposição ao trabalhador do campo, que já existia e se relacionava com a terra sem este elemento rentista, que o subordinaria ao capital. Aqui cabe uma pequena crítica ao autor já que mesmo diante de todas as incoerências teóricas e políticas que estes mediadores políticos apresentavam na sua conduta, não se pode negar que sua presença em inúmeros conflitos foi fundamental para a conquista seja da posse da terra, seja de direitos trabalhistas, seja do próprio reconhecimento político desses sujeitos "ocultos". Além do mais na sociedade em que vivemos é assim que os grupos se fazem representar e reconhecer e é também por demandas de inclusão social que se sobrevive. Há também a ressalva de que apesar da "incompreensão" destes setores sobre quem seria este campesinato a ser representado, não poderia haver, como parece sugerir Martins, um tipo ideal de camponês a ser representado. Haveria de fato uma representação fiel e plenamente eficaz destes atores políticos? Ou trata-se de um desejo romantizado de que os próprios sujeitos se levantassem sem intermediação política de outros setores da sociedade elaborando um tipo puro de ação coletiva e representação política?

Outra especificidade estaria de que os processos decorrentes destas contradições não colocam posseiros, índios e outros trabalhadores silvícolas na condição de proletariado rural, impondo limites históricos a universalização da luta socialista emplacada pelo Partido Comunista e pelos sindicatos de trabalhadores rurais.

No livro “A militarização da questão agrária” (1984), Martins retoma as dimensões políticas do problema, não apenas do ponto de vista das representações, mas sobre tudo a partir da perspectiva da ação autoritária do Estado no regime militar. O modo como a política fundiária foi elaborada e implementada demonstra a diversidade interna e as múltiplas posições dentro dos governos militares. Mas é certo de que houve um esforço no sentido de, por um lado, fortalecer a empresa agropecuária em especial na região amazônica, também com intuitos de assegurar o controle territorial do país através da aliança entre militares e capital privado; e, por outro, de atenuar os conflitos sociais mais proeminentes e que representavam perigo a estabilidade institucional do regime. 
Houve de fato uma rearticulação de forças sociais a partir do momento em que, com a centralização das políticas fundiárias, retirou-se o poder absoluto de oligarquias regionais e regulamentou-se uma série de relações de trabalho, de exploração do solo e de acesso aos subsídios do governo. Entretanto, na opinião de Martins, a forma institucional que assumiu a ação do Estado, a exemplo do Grupo Executivo de Terras do Araguaia-Tocantins (GETAT), que veio sobrepor-se ao INCRA e ao Judiciário, veio reforçar uma espécie de "coronelismo de Estado" já que "[...] coordena a 'solução' do problema da terra e (...) faz exatamente o papel do 'coronel', concede dádivas, acomoda, tenta conciliar, etc., para garantir os interesses dos grandes proprietários" (MARTINS, 1984, p. 73).

Assim, o Estado tem sua conduta política orientada pelo que o autor vai chamar mais tarde de "cartorial e clientelista". Mas esta conotação não se define apenas pela ação direta sobre a questão agrária ou fundiária, está marcada pela ampliação da infraestrutura econômica de regiões não urbanizadas, medida que se faz pela transferência de renda de outros setores para aqueles de base agrária (MARTINS, 1989). Base agrária cuja reprodução social e econômica não se encontra na produção agropecuária, mas na ação especulativa sobre a terra.

Intrigante é que esta especulação tem seus marcos legais e institucionais e tem nas políticas de colonização sua legitimidade, já que através de seus domínios territoriais e empresas rurais são impulsionadores e provedores de projetos de colonização que agregam tanto a ideia de domesticação e urbanização de regiões inóspitas, como o ímpeto desenvolvimentista da industrialização do campo. Já nos anos 1950-70 e agora nos anos 1990-2000 as políticas de migração e colonização, respectivamente, configuram o modelo legalmente reconhecido e amparado pelo Estado de extração da renda territorial pelo capital privado. A política de incentivos, segundo o sociólogo, “[...] destinou-se claramente a proteger a renda fundiária e os proprietários de terra, assegurando sua permanência na estrutura de poder. (...) preservando e modernizando a propriedade, ao mesmo tempo, sem fazer reforma sociais" (MARTINS, 1989, p. 83).

Já nos anos 2000, parece haver uma reviravolta na percepção de Martins quanto à atuação do Estado no que se refere ao problema agrário. Mesmo considerandoo ainda uma questão política, enxerga ao longo do tempo mudanças substantivas na orientação do então governo e aponta em alguns momentos a importância das leis 
Propriedade da terra e poder no Brasil na obra de José de Souza Martins

reconhecendo que desde de que o Estado faça cumprir a Lei avanços políticos na democracia podem ser alcançados. Há de se considerar que o surgimento de novos sujeitos políticos submete à crítica permanente e desequilibra o monopólio político dos grupos dominantes, ao mesmo tempo em que os força a repensar estratégias de legitimação de suas práticas (MARTINS, 1989). Se por um lado o viés autoritário e repressor foi parcialmente suprimido com a abertura democrática e em nome das liberdades democráticas, temos o enquadramento legal de novas ações de resistência e combate às formas de exploração e de expropriação que os trabalhadores e seus grupos organizados vem realizando.

Mas estas transformações ocorridas na sociedade brasileira, consequentemente no Estado também, podem, segundo Martins, ter aspectos positivos para a questão agrária. "Trata-se do estabelecimento de progressivas, ainda que lentas, limitações ao exercício do direito de propriedade em nome não só de sua função social, mas também de sua função política na soberania do Estado" (MARTINS, 2000, p. 124). Para escapar ao problema dos desencontros entre os que reivindicam políticas sociais (como a política de reforma agrária) e os mediadores políticos e institucionais ${ }^{6}$, a questão fundiária foi trazida para as esferas institucionais e tomada enquanto questão de Estado, não dependendo mais da ação política, reivindicatória e contestatória historicamente feita pelos movimentos sociais. Entretanto, interpelando a si mesmo e à História afirma que “[...] o regime de propriedade envolveu tão intensamente as instituições, em especial o Judiciário, ao longo da história republicana, que se tornou impossível fazer uma reforma agrária que não passe pelo pagamento da uma substancial renda fundiária aos proprietários" (MARTINS, 2000, p.125).

\section{CONSIDERAÇÕES FINAIS}

Tendo como foco de sua análise as formas assumidas pelas contradições do capital, numa sociedade cuja característica principal é um desenvolvimento desigual e em que tempos históricos distintos se encontram ou desencontram dialeticamente, José de Souza Martins aponta a propriedade privada da terra como eixo central seja das alianças entre elites proprietárias de terra e o grande capital mediadas pelo Estado, seja da exclusão de direitos de grupos sociais cuja relação com a terra não é apenas mercantil. Segundo Soto, trata-se “[...] de entender a lógica da expansão do capitalismo 
no campo, operando transformações profundas nas relações sociais" (SOTO, 2002, p. 125).

Ao abordar a propriedade privada da terra como um processo social, cuja principal consequiência é a sujeição do trabalho à renda capitalizada, Martins analisa o processo histórico de expropriação de terras de camponeses e trabalhadores rurais que, por sua vez, lutam num exercício de resignificar a noção de direito e também de propriedade da terra. Na medida em que fazem o embate com as formas jurídicas e econômicas do capital, defrontam-se com elementos tradicionais da dominação patronal, tanto na figura do fazendeiro como na figura do Estado. Estado este que como vimos assumiu a forma capitalista a partir da elaboração e manutenção de um arcabouço jurídico democrático que articula formas modernas com conservadoras de apropriação da terra e do trabalho.

Ao pensar a propriedade da terra em termos de relações sociais vislumbrase, através das lutas sociais no campo, o embate que se dá entre os diferentes sujeitos políticos e as respectivas concepções de propriedade da terra (privada, comunal, morgadio, etc.). Porém, deve-se considerar que é também no pólo do consumo e da redistribuição das riquezas que se encontra o caráter social e coletivo da exploração do homem pobre do campo e não especificamente nas relações de trabalho. Este embate nos remete a disputa desigual entre terras de subsistência e um mercado especulativo de terras. "Para Martins, essa pressão do capital sobre as terras que produzem os meios de subsistência gera a crise social no campo e essa contradição constitui a base dos conflitos sociais no mundo rural" (SOTO, 2002, p.127).

Contrariando as teses de universalização do assalariamento no campo, ou da proletarização dos camponeses e de trabalhadores rurais em geral, Martins aponta a renda territorial capitalizada como mediadora que singulariza as relações de dominação e sujeição no campo. Assim, qualquer modelo de representação e/ou mediação política, ou mesmo de ação política governamental, que não pensar todos os elos desta cadeia produtiva, integrada no rural e no urbano, tenderá a perpetuar a irracionalidade básica do capitalismo brasileiro, a renda fundiária.

A ideia de personificação do capital, presente no livro "O cativeiro da Terra" lembra que atentar para as formas mediadoras dessas relações sociais é indispensável para o entendimento do que é tenso e contraditório no mundo rural. 
Propriedade da terra e poder no Brasil na obra de José de Souza Martins

Ao focar o caráter institucional da propriedade privada, revela-se a diversidade das formas coercitivas de regulação e normatização da ação social, seja de trabalhadores, seja de proprietários. É latente a reprodução renovada de mecanismos de controle social, explícitos, por exemplo, na criminalização dos movimentos sociais, para além das próprias condições objetivas e econômicas tais como o mercado de terras e o de trabalho que delimitam as possibilidades de ação e representação dos sujeitos. Mas se consideramos os mecanismos atuais de reprodução do capital na sociedade brasileira não podemos esquecer que, se houve alguns avanços democráticos em termos de inclusão de uma massa de trabalhadores num sistema de assistência social e de uma pauta de proteção de direitos humanos. Resta saber que, como sugere Martins, estamos envolvidos num ciclo permanente de exploração que apesar de garantir direitos mantém afastados dos centros de decisão política os protagonistas destas lutas sociais, representantes reconhecidos pelo Estado e pela sociedade da luta pela terra.

Entretanto, mesmo identificando um acúmulo de forças e de experiências que possibilitaria melhores formas de representação e atuação política nos espaços institucionais de participação social, um estrangulamento jurídico do repertório de ações desses movimentos no sentido de acessar direitos sociais, vem sendo promovido e garantido por um Estado que se diz mínimo. A ação deste Estado se consolida na renovação e diversificação do monopólio da propriedade privada e nas alianças com os grandes proprietários de terra no Brasil, mantém como ideologia o progresso e o crescimento econômico sem justiça social e/ou distribuição de renda.

Ao tomar conhecimento da produção intelectual de José de Souza Martins, tem-se de fato a dimensão política da questão agrária no Brasil, desde de que é Brasil, como um problema estrutural. A superação deste impasse deve passar fundamentalmente por uma crítica que não basta ser severa, mas deve se propor reveladora das relações de poder estabelecidas em torno da propriedade privada da terra, para quem sabe apontar alternativas de efetivamente mais democráticas de acesso à terra.

\section{REFERÊNCIAS}

MARTINS, José de Souza. A imigração e a crise do Brasil agrário. São Paulo: Pioneira, 1973. 
. Capitalismo e tradicionalismo. Estudo das contradições da sociedade agrária no Brasil. São Paulo: Pioneira, 1975.

. O Cativeiro da Terra. São Paulo: Livraria Editora Ciências Humanas, 1979.

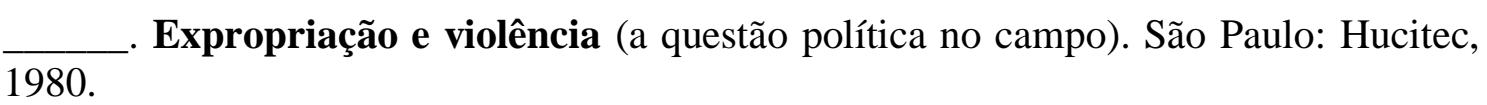

. Camponeses e a política no Brasil. Petrópolis: Vozes, 1981. . (org.). Introdução à crítica da sociologia rural. São Paulo: Hucitec, 1981.

. A militarização da questão agrária no Brasil. Petrópolis: Vozes, 1984.

. Caminhada no chão da noite. São Paulo: Hucitec, 1989.

. A chegada do estranho. São Paulo: Hucitec, 1993.

$\overline{\text { Hucitec, }} 1994$.

O poder do atraso. Ensaios de sociologia da história lenta. São Paulo: (org.). Henri Lefebvre e o retorno à dialética. São Paulo: Hucitec, 1996.

$\overline{\text { Hucitec, }} 1997$.

Fronteira. A degradação do Outro nos confins do humano. São Paulo: - Sociologia e militância. Entrevista com José de Souza Martins. Revista Estudos Avançados, 11 (31), São Paulo: EDUSP, 1997.

. Reforma agrária: o impossível diálogo. São Paulo: Hucitec, 2000.

O Sujeito Oculto. Porto Alegre: Ed. UFRGS, 2003.

SOTO, William Héctor Gómez. A produção sobre o "mundo Rural” no Brasil. As contribuições de José de Souza Martins e José Graziano da Silva. Santa Cruz do Sul: EDUNISC, 2002.

Artigo recebido em 18 de dezembro 2018 e aceito em 31 de dezembro de 2018

${ }^{1}$ Cabe esclarecer que esta separação entre processos, relações e instituições sociais tem caráter
analítico e não se verificam empiricamente. A ideia de uma abordagem sincrônica destes
elementos tem como propósito apreender as conexões entre ambos, enquanto a perspectiva 
diacrônica busca justamente averiguar rupturas e continuidades das estruturas e dos agentes sociais na História recente brasileira, a partir da obra de José de Souza Martins.

${ }^{2}$ Em que acadêmicos e políticos debatiam a natureza do desenvolvimento econômico brasileiro em termos de oposições binárias, tais como feudal $\mathrm{x}$ capitalista, atrasado $\mathrm{x}$ moderno, periferia $\mathrm{x}$ centro.

${ }^{3}$ Nos ensaios sob o título "Introdução crítica à Sociologia Rural", de 1981, Martins desenvolve longamente suas ideias sobre o que é o rural na sociedade e nas análises científicas e políticas, em termos teóricos e práticos, e suas consequências históricas.

${ }^{4}$ Vale ressaltar que estou utilizando o termo "relações/forma não capitalistas de produção" tal como o autor sugere. Reconheço, entretanto, que um enorme debate acerca da utilização destas noções foi travado entre uma série inumerável de autores, ao longo de duas ou três gerações da produção intelectual sobre o desenvolvimento do capitalismo brasileiro. Entendo aqui por relações não capitalistas aquelas não regulamentadas e enquadradas na legislação trabalhista ou que não tem como fim principal a obtenção do lucro, mas a reprodução de um modo de vida específico. O meu interesse neste termo não está na sua definição e classificação, mas sim no entendimento de como podem coexistir diferentes formas de reprodução social num mesmo modelo de desenvolvimento ampliado do capital, sempre no caso brasileiro.

${ }^{5}$ Martins não aponta motivos para a associação ou identificação entre camponeses a não ser pela situação de expropriação ou exclusão, num primeiro momento, e de exploração num segundo. Neste aspecto aproxima-se da análise presente na obra "O Dezoito Brumário de Luis Bonaparte" em que Marx tem o mesmo raciocínio e, no limite, chama os camponeses de "saco de batatas".

${ }^{6} \mathrm{O}$ que para Martins parece não ter acontecido com o Estado na figura dos Governos FHC (1994-2002). 